This item was submitted to Loughborough's Research Repository by the author.

Items in Figshare are protected by copyright, with all rights reserved, unless otherwise indicated.

\title{
The effects of soot properties on the regeneration behaviour of wall-flow diesel particulate filters
}

PLEASE CITE THE PUBLISHED VERSION

PUBLISHER

Professional Engineering Publishing / @ IMECHE

VERSION

VoR (Version of Record)

LICENCE

CC BY-NC-ND 4.0

\section{REPOSITORY RECORD}

Law, Ming-Chiat, Andrew Clarke, and Colin P. Garner. 2019. "The Effects of Soot Properties on the Regeneration Behaviour of Wall-flow Diesel Particulate Filters". figshare. https://hdl.handle.net/2134/4836. 
This item was submitted to Loughborough's Institutional Repository (https://dspace.lboro.ac.uk/) by the author and is made available under the following Creative Commons Licence conditions.

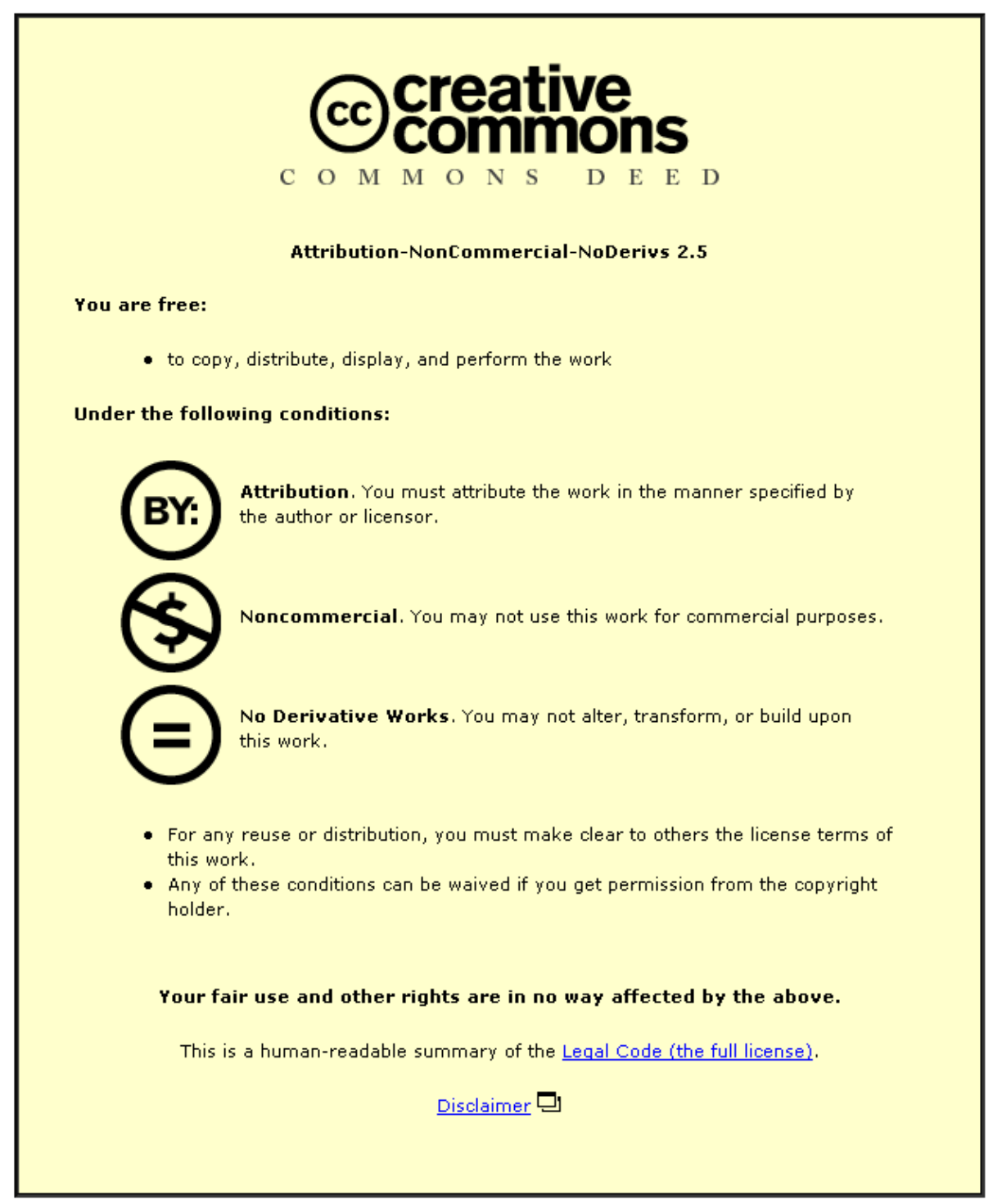

For the full text of this licence, please go to: http://creativecommons.org/licenses/by-nc-nd/2.5/ 


\title{
The effects of soot properties on the regeneration behaviour of wall-flow diesel particulate filters
}

\author{
M C Law, A Clarke and C P Garner* \\ Wolfson School of Mechanical and Manufacturing Engineering, Loughborough University, Loughborough, UK
}

\begin{abstract}
In recent years, significant effort has been put into studying the regeneration process of diesel particulate filters (DPFs) either through experiments or modelling. However, less attention is paid to understanding the important influence of soot properties on the regeneration process. In this paper, for the first time, five fundamental soot properties, namely activation energy, frequency factor of the reaction, soot bulk density, porosity and mean soot particulate diameter, are investigated. Sensitivity analyses are carried out for each of these parameters based on a one-dimensional generalized DPF regeneration model. It is found that activation energy is the most important factor in the regeneration process, followed by frequency factor, bulk density, porosity and mean particulate size. In addition, the results also indicate that the concentration of exhaust gas oxygen has a significant influence on the role played by each parameter. This clearly shows the importance of gas diffusion in the regeneration process.
\end{abstract}

Keywords: regeneration, oxidation, soot, diesel particulate filter, trap, activation energy, frequency factor, bulk density, porosity, particle size

\section{NOTATION}

a specific area $\left(\mathrm{m}^{-1}\right)$

$A \quad$ frequency factor $\left(\mathrm{s}^{-1}\right)$

$A_{\text {fil }} \quad$ total filtration projected area $\left(\mathrm{m}^{2}\right)$

$b \quad$ mass transfer rate $\left(\mathrm{s}^{-1}\right)$

$c_{p} \quad$ specific heat capacity at constant pressure $(\mathrm{kJ} / \mathrm{kg} \mathrm{K})$

d diameter $(\mathrm{m})$

$E_{\text {a }} \quad$ activation energy $(\mathrm{kJ} / \mathrm{kmol})$

$g$ mass transfer conductance $\left(\mathrm{kg} / \mathrm{m}^{2} \mathrm{~s}\right)$

$G \quad$ gas flowrate $(\mathrm{kg} / \mathrm{s})$

$h \quad$ convective heat transfer coefficient

$\left(\mathrm{kJ} / \mathrm{s} \mathrm{m}^{2} \mathrm{~K}\right)$

$H \quad$ enthalpy of reaction $(\mathrm{kJ} / \mathrm{kg})$

$k_{\mathrm{S}} \quad$ bulk thermal conductivity of porous solid $(\mathrm{kJ} / \mathrm{s} \mathrm{m} \mathrm{K})$

$K \quad$ chemical reaction rate $\left(\mathrm{s}^{-1}\right)$

$m$ mass fraction (-)

$r \quad$ stoichiometric ratio $(-)$

$R_{\mathrm{u}} \quad$ universal gas constant $(\mathrm{kJ} / \mathrm{kmol} \mathrm{K})$

$t \quad$ time (s)

The MS was received on 4 August 2003 and was accepted after revision for publication on 23 July 2004.

* Corresponding author: Wolfson School of Mechanical and Manufacturing Engineering, Loughborough University, Loughborough, Leicestershire, LE113TU, UK. email: C.P.Garner@Lboro.ac.uk

$\begin{array}{ll}T & \begin{array}{l}\text { absolute temperature }(\mathrm{K}) \\ z\end{array} \\ Z & \begin{array}{l}\text { coordinate }(\mathrm{m}) \\ \text { total thickness (particulate, ceramic or } \\ \text { combined) }(\mathrm{m})\end{array} \\ & \\ \beta_{\mathrm{p}} & \begin{array}{l}\text { mass concentration of particulate per unit } \\ \text { volume (bulk density) }\left(\mathrm{kg} / \mathrm{m}^{3}\right)\end{array} \\ \eta & \begin{array}{l}\text { general gas constituent }(-) \\ \text { density }\left(\mathrm{kg} / \mathrm{m}^{3}\right)\end{array} \\ \rho & \text { medium porosity }(-)\end{array}$

\section{Subscripts}

G gas phase

$\mathrm{O}_{2} \quad$ oxygen

$\mathrm{p} \quad$ particulate

pore ceramic pore

Reg regeneration

S solid phase

w wall

\section{Superscripts}$$
\text { " }
$$$$
\text { ' }
$$

per unit area $\left(\mathrm{m}^{-2}\right)$ per unit volume $\left(\mathrm{m}^{-3}\right)$ derivative with respect to time $\left(\mathrm{s}^{-1}\right)$

Proc. Instn Mech. Engrs Vol. 218 Part D: J. Automobile Engineering 


\section{INTRODUCTION}

Forthcoming light- and heavy-duty diesel vehicle exhaust emissions legislation, such as Euro V and US Tier 4, will require substantial reductions in particulate levels. To meet these levels, exhaust particulate filters (or 'traps') are likely to be required since they have high filtration efficiencies and can reduce engine-out particulate emissions by $60-99$ per cent.

There are a variety of diesel particulate filters (DPFs) available, including the wall-flow monolith, fibrous mesh and foams. Of these, the wall-flow monolith DPF shows the highest filtration efficiency, which is usually over 95 per cent. The wall-flow monolith (Fig. 1) consists of a ceramic honeycomb of square channels, typically $1-2 \mathrm{~mm}$ in square cross-section with each end of channel plugged alternately. Hence, the exhaust gas flow is forced to pass through the porous walls between the channels. The pore size of the wall is such that it is able to filter some of the particulates in the wall. As time proceeds, soot particulates start to accumulate on the wall surface. The soot forms a layer on the wall surface that encourages the trapping of subsequent particulates. This gives rise to the high filtration efficiency.

If the soot is allowed to accumulate too much, both the engine power and the fuel economy deteriorate due to excessive exhaust gas back pressures. To avoid this, the filter is cleaned or 'regenerated' by a variety of methods, including fuel burners, electrical heaters and catalysts $[\mathbf{1}, \mathbf{2}]$. The regeneration process, in which the trapped particulate/soot burns, is poorly understood and its controls a particularly difficult technical challenge. During regeneration, heat is liberated by the soot and, if uncontrolled, can lead to thermal runaway and eventual filter failure by melting. Conversely, if the combustion rate is too low, the regeneration process can extinguish prematurely leading to incomplete filter regeneration.

A number of models have been developed to understand the regeneration processes by each method [3-7]. The fundamental limitations of these models to date have been the lack of the knowledge with regard to soot properties and the regeneration behaviour in the DPF. Hence, this paper studies the influence of four important and fundamental soot properties on the regeneration

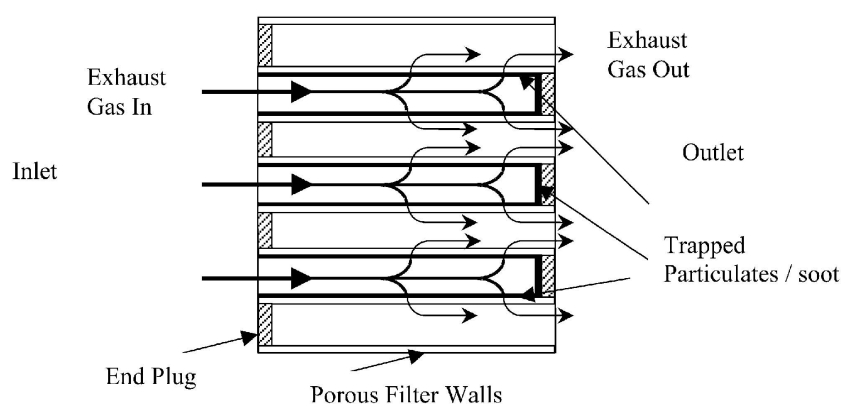

Fig. 1 Schematic diagram of a wall-flow monolith DPF process using a generalized DPF regeneration model. In the following section, the model, which was originally developed by Garner and Dent [7], is described. A selection of some previously published results are given in section 3 to illustrate how the model behaves. Using this model, a sensitivity analysis of results of varying five important soot properties on regeneration behaviour is presented and the results are discussed in sections 4 and 5 respectively. The results have significant value for modelling and experimental studies of filter regeneration behaviour.

\section{DESCRIPTION OF MODEL}

\subsection{DPF physical structure}

In the model, the physical DPF structure is transformed such that all the soot particulates are distributed evenly on a ceramic/cordierite slab as shown in Fig. 2. The structure consists of a layer of reactant (soot) and it is followed by an inert ceramic slab. The area (i.e. the surface where the soot accumulates) is equal to the total filtration area of the actual DPF, $A_{\text {fil }}$. The thickness of the ceramic slab is equal to a single channel wall. The mean exhaust gas flow is assumed normal to the ceramic slab.

\subsection{Regeneration mechanism}

In this model, a one-step global heterogeneous reaction $\mathrm{C}(\mathrm{s})+\mathrm{O}_{2}(\mathrm{~g}) \rightarrow \mathrm{CO}_{2}(\mathrm{~g})$ is considered as a forward oneway reaction. For oxidation of soot to occur, oxygen must be transported to the surface of the soot layer. Here, a distinction is made between the input concentration of oxygen and that involved in the regeneration process. The former is denoted as $m_{\mathrm{G}, \mathrm{O}_{2}}$ and the latter $m_{\mathrm{S}, \mathrm{O}_{2}}$. Thus, the rate of transport of oxygen per unit volume is given by

$$
\dot{G}_{\mathrm{G}, \mathrm{O}_{2}}^{\prime \prime \prime}=g a\left(m_{\mathrm{G}, \mathrm{O}_{2}}-m_{\mathrm{S}, \mathrm{O}_{2}}\right)
$$

where $g$ is the mass transfer conductance and $a$ is the specific area of the soot. The rate of oxygen consumption

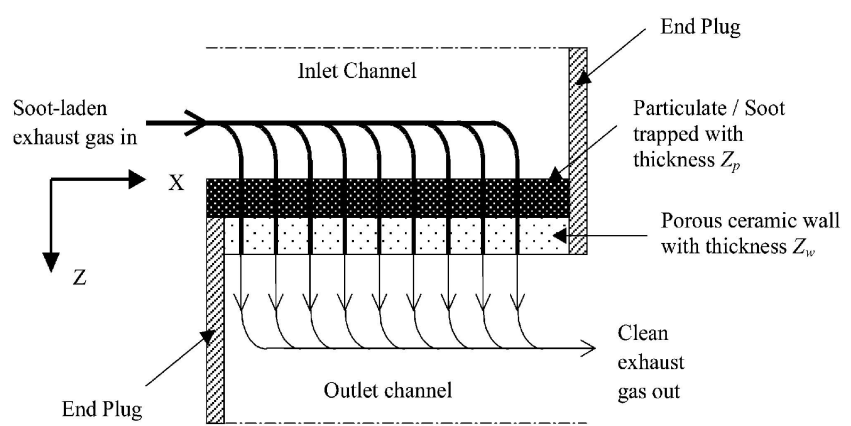

Fig. 2 Schematic diagram of a single pair of inlet and outlet channels on which the model is based 
at the soot surface is expressed as

$$
\dot{R}_{\mathrm{S}, \mathrm{O}_{2}}^{\prime \prime \prime}=K \rho_{\mathrm{G}} m_{\mathrm{S}, \mathrm{O}_{2}}
$$

where $K$ is chemical reaction rate and $\rho_{\mathrm{G}}$ is the bulk gas density.

During the steady state, the rate of oxygen transfer from bulk gas to soot surface equals the rate of oxygen consumption at the surface. Thus

$$
\dot{G}_{\mathrm{G}, \mathrm{O}_{2}}^{\prime \prime \prime}=\dot{R}_{\mathrm{S}, \mathrm{O}_{2}}^{\prime \prime \prime}
$$

Equations (1) and (2) are solved for the unknown oxygen mass fraction at the surface; thus

$$
m_{\mathrm{S}, \mathrm{O}_{2}}=\frac{g a}{K \rho_{\mathrm{G}}+g a} m_{\mathrm{G}, \mathrm{O}_{2}}
$$

Equation (4) is substituted into equation (2), and the result is divided by $\rho_{\mathrm{G}}$; thereby an expression for the rate of oxygen consumption is obtained as

$$
\dot{R}_{\mathrm{S}, \mathrm{O}_{2}}^{\prime \prime \prime}=\frac{K b}{K+b} \rho_{\mathrm{G}} m_{\mathrm{G}, \mathrm{O}_{2}}
$$

where $b=g a / \rho_{\mathrm{G}}$. Equation (5) explicitly shows the dependence on both kinetic and diffusion reactions despite most of the existing models assuming only a kinetic-controlled reaction rate.

\subsection{Mass balance}

\subsubsection{Particulate}

The mass of particulate is depleted as it is oxidized and is represented by the expression

$$
\frac{\partial \beta_{\mathrm{p}}}{\partial t}=-\frac{\dot{R}_{\mathrm{S}, \mathrm{O}_{2}}^{\prime \prime \prime}}{r}
$$

where $\beta_{\mathrm{p}}$ is the bulk density of soot/particulate and $r$ is the stoichiometric ratio of the reaction.

\subsubsection{Exhaust gas stream}

Since oxygen is transferred from the exhaust gas stream to the particulate surface and carbon dioxide is transferred back to the gas stream, the gradients of these two constituents will exist in the direction of the flow and with respect to time. Reactions of other species can be accommodated in the model since the mass transfer and gradient expressions are written in a general form. For a general constituent $\eta$ in the gas flow the gradients of concentration in space and time are given by

$$
-\phi \dot{G}_{\mathrm{G}}^{\prime \prime} \frac{\partial m_{\mathrm{G}, \eta}}{\partial z}-\phi \rho_{\mathrm{G}} \frac{\partial m_{\mathrm{G}, \eta}}{\partial t}=g a\left(m_{\mathrm{G}, \eta}-m_{\mathrm{S}, \eta}\right)
$$

where $\phi$ is the medium porosity, $\dot{\mathrm{G}}_{\mathrm{G}}^{\prime \prime}$ is the gas flowrate per unit area, and $m_{\mathrm{G}, \eta}$ and $m_{\mathrm{S}, \eta}$ are the concentration of gas constituent $\eta$ in the bulk gas and at the solid surfaces respectively. For oxygen transport to the particulate surface and consumption there, equation (7) may be rewritten as

$$
-\phi \dot{G}_{\mathrm{G}}^{\prime \prime} \frac{\partial m_{\mathrm{G}, \mathrm{O}_{2}}}{\partial z}-\phi \rho_{\mathrm{G}} \frac{\partial m_{\mathrm{G}, \mathrm{O}_{2}}}{\partial t}=\dot{R}_{\mathrm{S}, \mathrm{O}_{2}}^{\prime \prime \prime}
$$

\subsection{Energy balance}

\subsubsection{Gas stream}

Since the filter is well insulated, radiation effects in the gas stream can be neglected. Therefore, the loss of energy in the gas flow with time and in the flow direction is equal to the heat convected to the solid surface. This is expressed as

$$
-\phi \dot{G}_{\mathrm{G}}^{\prime \prime} c_{p \mathrm{G}} \frac{\partial T_{\mathrm{G}}}{\partial z}-\phi \rho_{\mathrm{G}} c_{p \mathrm{G}} \frac{\partial T_{\mathrm{G}}}{\partial t}=h a\left(T_{\mathrm{G}}-T_{\mathrm{S}}\right)
$$

where $h$ is the convective heat transfer coefficient. Note that a distinct gas temperature $T_{\mathrm{G}}$ and solid temperature $T_{\mathrm{S}}$ are assumed here, which is consistent with that of recent researchers [8]. Early models developed by previous investigators [9] have assumed these two phases to be at the same temperature. While this is a fair approximation, it would restrict the general nature of the model equations if assumed here.

\subsubsection{Solid phase}

Radiative heat transfer effects can be neglected since the channels are slender and each of the four surfaces of the inlet channel is assumed to exchange equal amounts of radiative heat with each other. The convective heat transfer to the solid from the gas stream increases the internal energy of the solid, and hence its temperature, setting up a thermal gradient due to conduction in the flow direction. If the temperature of the solid is high enough, the particulate will oxidize rapidly, liberating significant energy. This can be expressed as

$$
(1-\phi) \rho_{\mathrm{S}} c_{p \mathrm{~s}} \frac{\partial T_{\mathrm{S}}}{\partial t}=\dot{R}_{\mathrm{S}, \mathrm{O}_{2}}^{\prime \prime \prime} H+h a\left(T_{\mathrm{G}}-T_{\mathrm{S}}\right)+k_{\mathrm{S}} \frac{\partial^{2} T_{\mathrm{S}}}{\partial z^{2}}
$$

where $\rho_{\mathrm{S}}$ is the solid density, $H$ is the enthalpy of reaction for particulate oxidation and $k_{\mathrm{S}}$ is the bulk thermal conductivity of the porous solid.

\subsection{Equation of state}

Since the change in gas pressure in the filter during the regeneration process is of the order of a few tens of torrs [10], the absolute gas pressure in the filter is assumed to be constant. The equation of state can therefore be 
expressed as

$$
\rho_{\mathrm{G}} T_{\mathrm{G}}=\mathrm{constant}
$$

\subsection{Solution algorithm}

The non-linear partial differential equations obtained were solved using the algorithm by Lawson and Norbury [11]. The initial and boundary conditions were used as first iterates to solve the energy equations using Newton's method. The resulting approximations were then used to solve for other unknowns by the GaussSeidel method. The algorithm is efficient and it takes only $2-3$ s for a 600 time-step simulation on a Pentium $4,1.8 \mathrm{GHz}$ personal computer.

\subsection{Application of model to monolithic wall-flow filters}

Up to this point, the above equations have been kept sufficiently general to model gas flow through a matrix containing reactive particulate. These general equations are now applied to the specific geometry of the monolithic wall-flow filter. It is possible to model other types of filter, e.g. fibrous [7] and foams using the same foregoing equations in a similar manner.

\subsubsection{Model geometry}

The model geometry described earlier and shown in Fig. 2 considers that oxidation takes place in the porous particulate deposit layer. The thickness of this layer is given by

$$
Z_{\mathrm{p}}=\frac{m_{\mathrm{p}}}{\beta_{\mathrm{p}} A_{\mathrm{fil}}}
$$

where $m_{\mathrm{p}}$ is the total filtered mass of particulate, $\beta_{\mathrm{p}}$ is the bulk density of the particulate and $A_{\text {fil }}$ is the total projected filtration area of the monolith. The regeneration equations are solved along the total length $Z$ of the model geometry, which includes the wall thickness $Z_{\mathrm{w}}$.

\subsubsection{Physical characteristics of the particulate layer}

The specific area of the solid is required for the heat and mass transfer rates. The particulate specific area depends on the size, density and shape of the particles. Although primary soot particles have diameters of the order of $10-30 \mathrm{~nm}$, these particles coalesce into larger agglomerates that have diameters of about $0.1-1 \mu \mathrm{m}$. The mean diameter based on a volume distribution was found to be $0.17 \mu \mathrm{m} \mathrm{[12]} \mathrm{and} \mathrm{this} \mathrm{value} \mathrm{was} \mathrm{chosen} \mathrm{as}$ the characteristic particle diameter.

Since there has been significant uncertainty concerning the bulk density of the particulate deposit, $\beta_{\mathrm{p}}$, a literature survey $[9,13-19]$ was conducted. It was found that the values used by many investigators ranged from 20 to $1800 \mathrm{~kg} / \mathrm{m}^{3}$ owing to different measurement methods. The present authors have found experimentally that monolithic filters fully loaded with diesel particulate consistently have particulate bulk densities of $56 \mathrm{~kg} / \mathrm{m}^{3}$ within a tolerance of about 5 per cent [20]. This was also in good agreement with previous results by some other investigators $[\mathbf{1 4}, \mathbf{2 1}]$. Therefore, the nominal value of $56 \mathrm{~kg} / \mathrm{m}^{3}$ was adopted for the purpose of the present work.

Depending on the particulate diameter, its specific area $a_{\mathrm{p}}$ varies. For an individual particle of density $\rho_{\mathrm{p}}$ the specific area is given by

$$
a_{\mathrm{p}}=\frac{6 \beta_{\mathrm{p}}}{d_{\mathrm{p}} \rho_{\mathrm{p}}}
$$

and, assuming a particle density of $2000 \mathrm{~kg} / \mathrm{m}^{-3}$ [22]

$$
a_{\mathrm{p}}=\frac{3 \times 10^{-3} \beta_{\mathrm{p}}}{d_{\mathrm{p}}}
$$

In monolithic wall-flow filters the exhaust gas containing oxygen flows through the fine particulate deposit and the heat and mass transfer mechanisms are not well understood. A comprehensive study of heat and mass transfer rates between non-reacting spheres in a gas flow has been given by Field et al. [23]. Pauli et al. [24] used the mass transfer equation derived by Thoenes and Kramers [17] for non-reacting spheres in their mathematical analysis of the regeneration of particulate filters. A mass transfer coefficient for a non-reactive system was also used by Wiedemann et al. [25] in the same application. For the work described here heat and mass transfer coefficients applicable to reacting beds of particles were used. Olson et al. [26] expressed the heat transfer coefficient as

$$
h_{\mathrm{p}}=3.787 \times 10^{-4}\left(\frac{\dot{G}_{\mathrm{G}}^{\prime \prime} T_{\mathrm{G}}}{\phi_{\mathrm{p}} d_{\mathrm{p}}}\right)^{0.5}
$$

and, assuming constant $\phi_{\mathrm{p}}=0.5$ and $d_{\mathrm{p}}=0.17 \mu \mathrm{m}$, this becomes

$$
h_{\mathrm{p}}=\operatorname{constant}\left(\dot{G}_{\mathrm{G}}^{\prime \prime} T_{\mathrm{G}}\right)^{0.5}
$$

It should be mentioned here that the high heat transfer rates encountered in packed beds are not due to high heat transfer coefficients but to the large contact area (i.e. large specific area) between the gas and the porous deposit layer. Olson et al. [26] also recommended an expression for the mass transfer conductance

$$
g_{\mathrm{p}}=9.806 \times 10^{-4}\left(\frac{\dot{G}_{\mathrm{G}}^{\prime \prime}}{\phi_{\mathrm{p}} d_{\mathrm{p}}}\right)^{0.5} T_{\mathrm{G}}^{0.33}
$$

Therefore, for constant $\phi_{\mathrm{p}}$ and $d_{\mathrm{p}}$ as before

$$
g_{\mathrm{p}}=\operatorname{constant}\left(\dot{G}_{\mathrm{G}}^{\prime \prime}\right)^{0.5} T_{\mathrm{G}}^{0.33}
$$

The mass transfer conductance $g_{\mathrm{p}}$ can also be found from the heat transfer coefficient using $g_{\mathrm{p}}=h_{\mathrm{p}} / c_{p \mathrm{G}}$ when the mass transfer rate is low, which is so for low values of $m_{\mathrm{G}, \mathrm{O}_{2}}-m_{\mathrm{S}, \mathrm{O}_{2}}$ and a Lewis number of unity. Hence from equation (16) the mass transfer conductance can 
be written as

$$
g_{\mathrm{p}}=\operatorname{constant}\left(\dot{G}_{\mathrm{G}}^{\prime \prime} T_{\mathrm{G}}\right)^{0.5}
$$

Equations (18) and (19) derived for $g_{\mathrm{p}}$ yield similar arithmetic results. For the present work, equation (19) was employed.

\subsubsection{Physical characteristics of the ceramic wall}

The specific area used here is based on the assumption of cylindrical pores of uniform diameter $d_{\text {pore }}$ and is given by

$$
a_{\mathrm{w}}=\frac{4 \phi_{\mathrm{w}}}{d_{\mathrm{pore}}}
$$

where $\phi_{\mathrm{w}}$ is the porosity of the ceramic wall.

A heat transfer coefficient correlation quoted by Bear and Corapcioglu [27] for flow through porous media yields

$$
h_{\mathrm{w}}=3.588 \times 10^{-3} k_{\mathrm{G}}\left(\frac{\dot{G}_{\mathrm{G}}^{\prime \prime}}{\mu_{\mathrm{G}}}\right)^{1.375} d_{\text {pore }}^{0.375}
$$

where $k_{\mathrm{G}}$ is the gas thermal conductivity and $\mu_{\mathrm{G}}$ is the gas dynamic viscosity.

Millet et al. [5] gave these as

$$
k_{\mathrm{G}}=1.49 \times 10^{-6} T_{\mathrm{G}}^{0.5}
$$

and

$$
\mu_{\mathrm{G}}=1.28 \times 10^{-6} T_{\mathrm{G}}^{0.5}
$$

Therefore

$$
h_{\mathrm{w}}=\operatorname{constant}\left(\dot{G}_{\mathrm{G}}^{\prime \prime}\right)^{1.375} T_{\mathrm{G}}^{-0.1875}
$$

for constant $d_{\text {pore }}$. The value of $d_{\text {pore }}$ for cordierite wallflow DPFs can vary between 15 and $25 \mu \mathrm{m}$ [28]. The NGK filter had a quoted mean $d_{\text {pore }}$ of $16.5 \mu \mathrm{m}$ and this value was used for the present model.

\subsubsection{Other data}

The chemical reaction rate $K$ is given by the Arrhenius equation

$$
K=A \exp \left(\frac{-E_{\mathrm{a}}}{R_{\mathrm{u}} T_{\mathrm{S}}}\right)
$$

where $A$ is the frequency factor, $E_{\mathrm{a}}$ the activation energy and $R_{\mathrm{u}}$ the universal gas constant.

It has been recommended [14] that activation energy values for carbon oxidation range from 70 to $420 \mathrm{~kJ} / \mathrm{mol}^{-1}$. Although values of frequency factor and activation energy depend on the mode of oxidation (thermal or catalytic), frequency factors for thermal oxidation used elsewhere $[\mathbf{9}, \mathbf{1 6}]$ differ by a factor of 2000.

Some of these reaction rates can yield unrealistic results and so the activation energy used by Pattas et al. [22] was adopted since their value was based on experimental results pertinent to monolithic wall-flow DPFs.
Their frequency factor $A$ was not defined in the form required in this study and so the nominal value of $1 \times 10^{5} \mathrm{~s}^{-1}$ was used. These values give a reaction rate within the range of those obtained by the different investigators quoted above.

Table 1 gives the data used for the present study of the monolithic filter.

\subsubsection{Engine data}

The diesel engine operating conditions used in the model are given in Table 2. For modelling purposes a simple regeneration method is adopted where the engine is operated at high load to obtain high exhaust gas temperatures. The engine is operated at light ( 24 per cent) load and increased at constant speed to a high (91 per cent) load in $30 \mathrm{~s}$, which in turn increases the exhaust gas temperature to promote filter regeneration. Although it is sometimes the practice to reduce the inlet gas temperature once rapid oxidation is under way, for the following results the temperature was maintained at a constant high level so that direct comparisons for different oxygen concentrations and filter loadings could be made.

\section{MODEL RESULTS}

The original results from the model have been previously published by Garner and Dent [7]. The modelling results were shown to be in good agreement with experimental findings obtained by Higuchi et al. [10]. Thus, only important selected results are highlighted here for the

\begin{tabular}{|c|c|}
\hline \multicolumn{2}{|l|}{ Ceramic monolith } \\
\hline Diameter & 5.66 in \\
\hline Length & 6.00 in \\
\hline \multicolumn{2}{|l|}{ Cell structure } \\
\hline Wall thickness, $Z_{\mathrm{w}}$ & 0.012 in \\
\hline Cell density & 200 cells/in ${ }^{2}$ \\
\hline Wall porosity $\phi_{\mathrm{w}}$ & 0.49 \\
\hline Mean pore diameter $d_{\text {pore }}$ & $16.5 \mu \mathrm{m}$ \\
\hline Specific heat capacity $c_{p \mathrm{w}}$ & $1.11 \mathrm{~kJ} / \mathrm{kg} \mathrm{K}$ \\
\hline Bulk density $\beta_{\mathrm{w}}$ & $1400 \mathrm{~kg} / \mathrm{m}^{-3}$ \\
\hline Bulk thermal conductivity $k_{\mathrm{w}}$ & $0.0011 \mathrm{~kW} / \mathrm{m} \mathrm{K}$ \\
\hline \multicolumn{2}{|l|}{ Particulate } \\
\hline Enthalpy of reaction, $H$ & $32800 \mathrm{~kJ} / \mathrm{kg}$ \\
\hline Activation energy $E_{\mathrm{a}}$ (nominal value) & $54.5 \mathrm{~kJ} / \mathrm{mol}$ \\
\hline Frequency factor $A$ (nominal value) & $1 \times 10^{5} \mathrm{~s}^{-1}$ \\
\hline Porosity $\phi_{\mathrm{p}}$ (nominal value) & 0.50 \\
\hline Mean diameter $d_{\mathrm{p}}$ & $0.17 \mu \mathrm{m}$ \\
\hline Specific heat capacity $c_{p p}$ & $1.51 \mathrm{~kJ} / \mathrm{kg} \mathrm{K}$ \\
\hline Bulk density $\beta_{\mathrm{p}}$ (nominal value) & $56 \mathrm{~kg} / \mathrm{m}^{3}$ \\
\hline Particle density $\rho_{\mathrm{p}}$ & $2000 \mathrm{~kg} / \mathrm{m}^{3}$ \\
\hline Bulk thermal conductivity $k_{\mathrm{p}}$ & $0.00084 \mathrm{~kW} / \mathrm{m} \mathrm{K}$ \\
\hline
\end{tabular}
purpose of understanding the model behaviour.

Figure 3a shows how the inlet exhaust gas and particulate-ceramic wall interface solid temperature vary with time. In the first $62 \mathrm{~s}$, the solid temperature is cooler than the inlet gas temperature, which heats the

Table 1 Data used for ceramic monolithic DPF model

Proc. Instn Mech. Engrs Vol. 218 Part D: J. Automobile Engineering 
Table 2 Model input based on a high-speed direct-injection 2.01 diesel engine

\begin{tabular}{ll}
\hline Exhaust gas temperatures at filter inlet & $473 \mathrm{~K}$ at $t=0 \mathrm{~s}$ (at $2750 \mathrm{r} / \mathrm{min}$ and $24 \%$ load) \\
& $773 \mathrm{~K}$ at $t=30 \mathrm{~s}$ (at 2750 r/min and $91 \%$ load) \\
Volumetric efficiency & $85 \%$ at $2750 \mathrm{r} / \mathrm{min}$ \\
Exhaust oxygen percentages & $3 \%, 5 \%, 7 \%, 10 \%, 15 \%$ \\
Exhaust gas pressure & $1 \mathrm{bar}$ \\
\hline
\end{tabular}
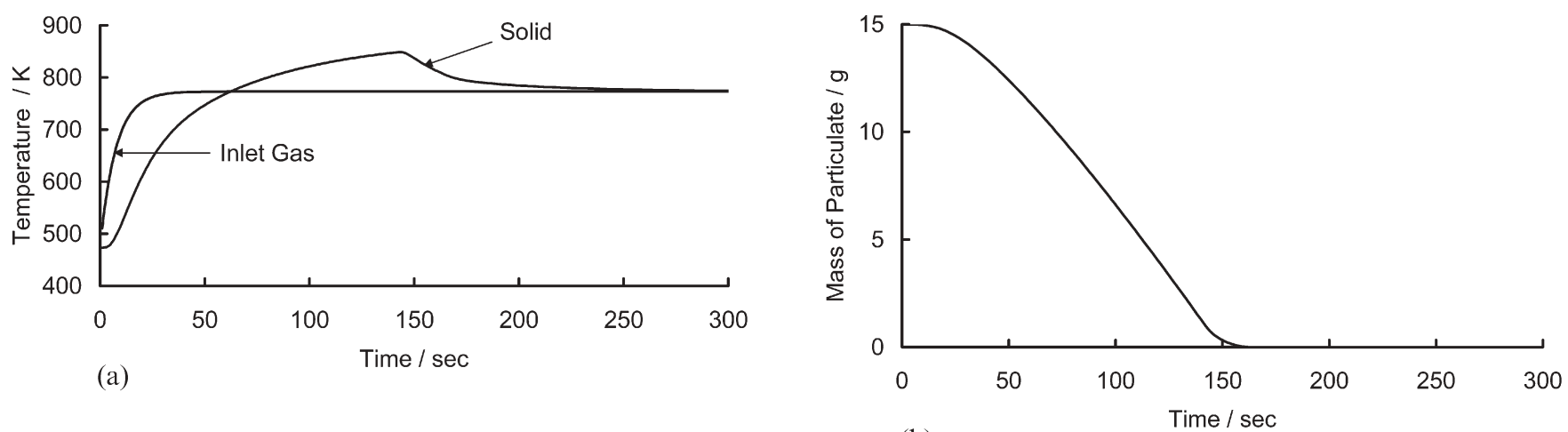

(b)
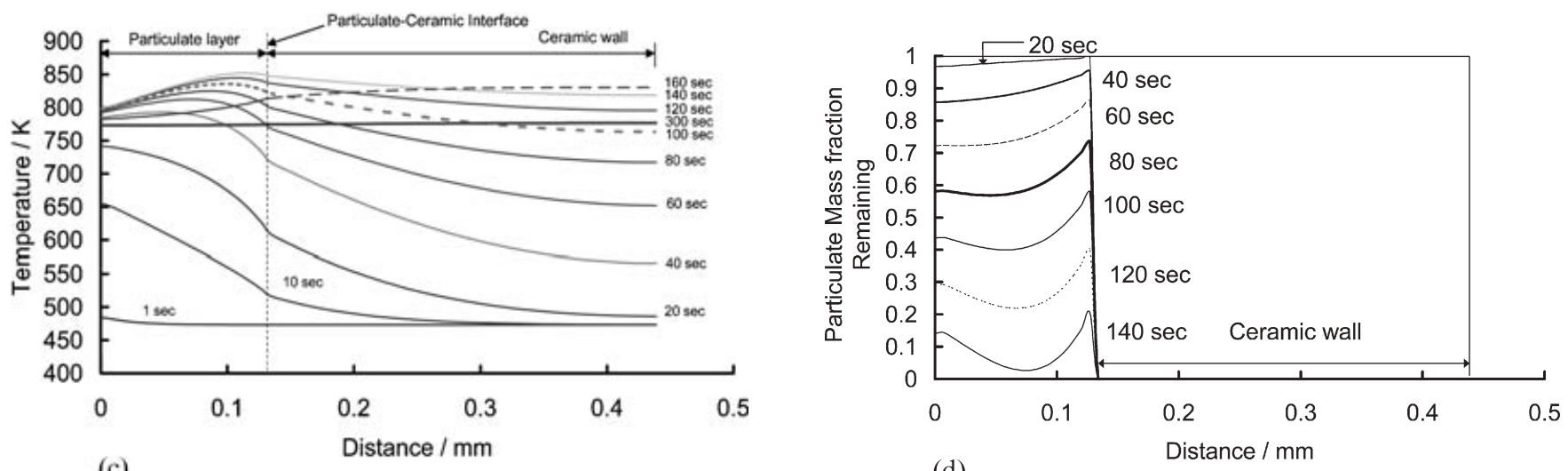

(d)

Fig. 3 (a) Temperature profiles for inlet exhaust gas and filter-soot particulate interface. (b) Change in particulate mass in a DPF during regeneration process. (c) Temperature profiles through the particulate layer and filter wall during regeneration. (d) Change in particulate mass during regeneration

filter matrix and causes some oxidation to occur on the particulate. Between 62 and $143 \mathrm{~s}$ the oxidation reaction liberates sufficient heat, causing the solid temperature to rise $75 \mathrm{~K}$ above the inlet gas temperature. At $143 \mathrm{~s}$ the reaction begins to cease since the particulate has been largely consumed and the filter matrix subsequently cools to the inlet gas temperature. Figure $3 \mathrm{~b}$ shows how the total particulate mass within the filter varies with time during the regeneration process. The minimal fresh particulate being filtered during regeneration is neglected.

The temperature variations across the composite slab are shown in Fig. 3c. Clearly the hottest part of the ceramic wall occurs adjacent to the particulate layer but the particulate layer itself reaches higher temperatures. The way in which the particulate layer oxidizes during regeneration is shown in Fig. 3d. The interior of the particulate layer reaches the highest temperatures and hence oxidizes at a faster rate.

\subsection{Effect of oxygen concentration and particulate mass}

The effects of oxygen concentration and soot accumulated in the DPF are presented in Figs 4 and 5. Here it can be seen that, although the high mass loadings lead to higher temperatures, the total regeneration time remains relatively constant. This is because the higher temperatures promote a faster oxidation rate but more particulate requires oxidizing.

The oxygen concentration has the most significant effect on the overall regeneration time, and both high oxygen concentration and high initial particulate mass loadings lead to high, and perhaps damaging, filter temperatures. To avoid filter melting, it is advisable to regenerate at low to mid-range particulate mass loadings.

More importantly, a modelling study shows that the particulate loading must be kept to below 25 per cent of total mass loading available in the filter (e.g. $10 \mathrm{~g}$ here) 

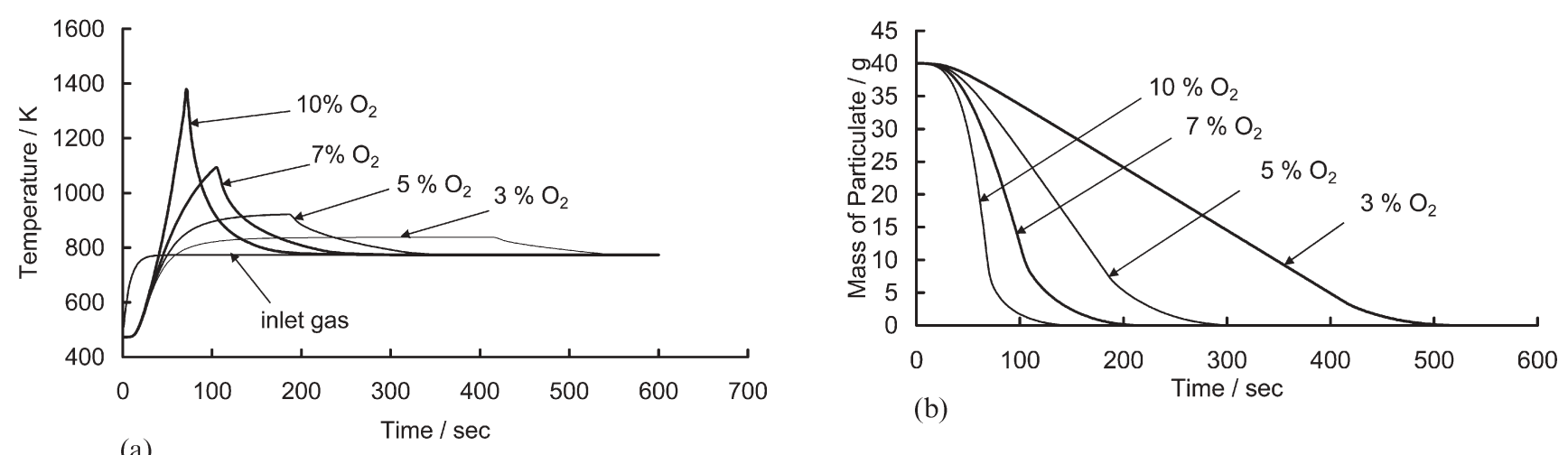

(a)

Fig. 4 (a) Temperature profiles of filter walls for various engine exhaust gas oxygen concentrations. (b) Effect of various engine exhaust gas oxygen concentrations on particulate oxidation time

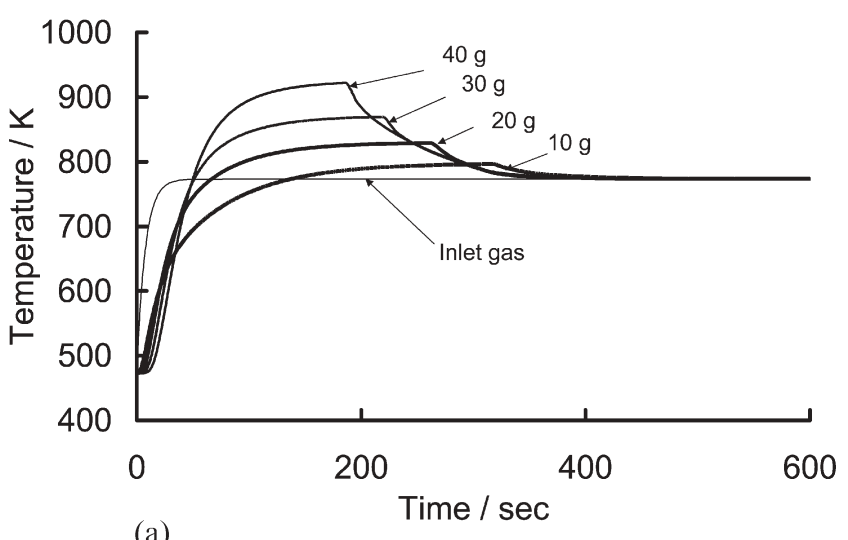

(a)

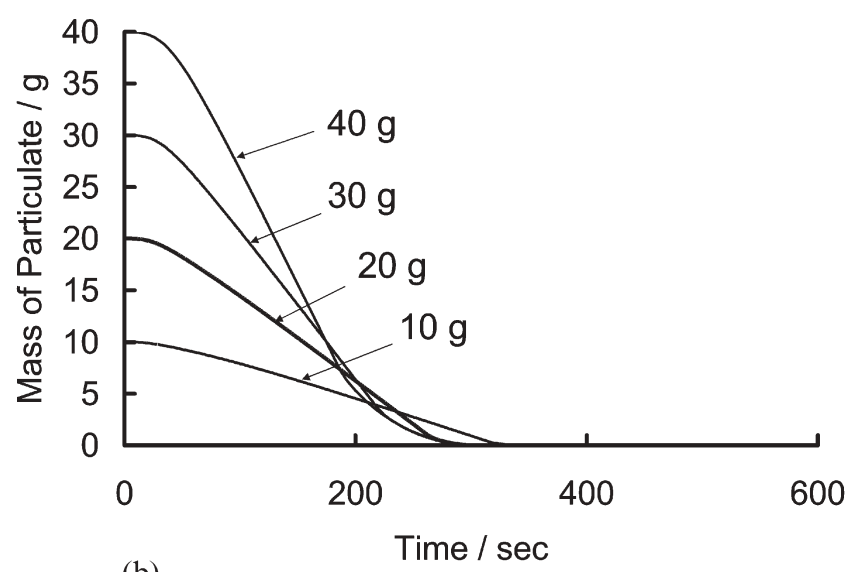

(b)

Fig. 5 (a) Effect of particulate mass on the maximum filter temperature. (b) Effect of particulate mass on the regeneration time in 5 per cent oxygen concentration

to ensure that exothermic temperature excursions are kept below a safe limit with all the expected exhaust oxygen levels.

\section{SENSITIVITY ANALYSIS}

This section reports the use of the model to study the effects of fundamental soot properties on the filter regeneration behaviour. Except for the activation energy $E_{\mathrm{a}}$, the literature survey conducted showed that there has been little research on the effect of soot properties on the regeneration behaviour of DPFs. Since it is believed that the soot properties play a significant role in this aspect, a study of the five soot properties is presented here. These properties include activation energy $E_{\mathrm{a}}$, frequency factor $A$, bulk density $\beta_{\mathrm{p}}$, soot porosity $\phi_{\mathrm{p}}$ and soot particle diameter $d_{\mathrm{p}}$. The first two parameters affect directly the rate of soot oxidation while the remaining parameters determine the heat transfer rate and the relative amount of soot and oxygen that are available to take part in the regeneration process in the DPF.
The activation energy $E_{\mathrm{a}}$ was varied between 47 and $62 \mathrm{~kJ} / \mathrm{mol}$ (i.e. 14 per cent either side of the nominal value of $54.5 \mathrm{~kJ} / \mathrm{mol}$ ) and their corresponding maximum temperatures were predicted using the model. This was carried out using three different oxygen concentrations, i.e. 5, 10 and 15 per cent. Similarly, the frequency factor was varied between $0.2 \times 10^{5}$ to $6.0 \times 10^{5} \mathrm{~s}^{-1}$ with the nominal base line of $1.0 \times 10^{5} \mathrm{~s}^{-1}$. In the analysis, the bulk density of soot was varied between 40 and $70 \mathrm{~kg} / \mathrm{m}^{3}$. Although both the soot bulk porosity and the density are interrelated quantities, the analysis assumed that they are independent of each other to help to understand the full variation in filter regeneration behaviour. The soot porosity parameter $\phi_{\mathrm{p}}$ was varied between 0 and 1 , which represent the states of perfect solid and fully oxidized respectively, in three different oxygen concentration environments. Recent diesel particulate number emission measurements have shown that 90 per cent of particles fall within the nano-range, i.e. diameters less than $50 \mathrm{~nm}$, despite being only 20 per cent on a mass basis [29]. The mean particulate diameter based on number weighting is about $20-30 \mathrm{~nm}$, whereas that based 
on mass weighting is $0.1-0.3 \mu \mathrm{m}$ [29]. Owing to the uncertainty in the mean particulate diameter, its sensitivity analysis was, therefore, studied for a range of sizes between $20 \mathrm{~nm}$ and $0.5 \mu \mathrm{m}$. The results for regeneration time versus parameters are presented in Fig. 6, and those for maximum filter temperature are in Fig. 7. These both indicate a relatively low sensitivity to particle diameter.

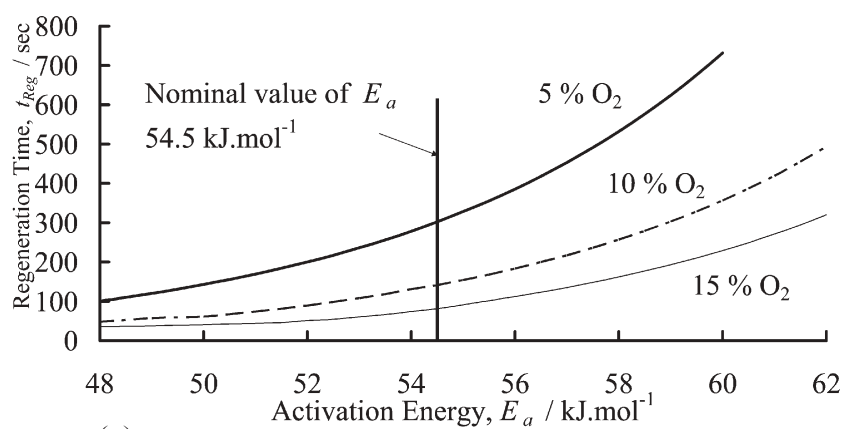

(a)

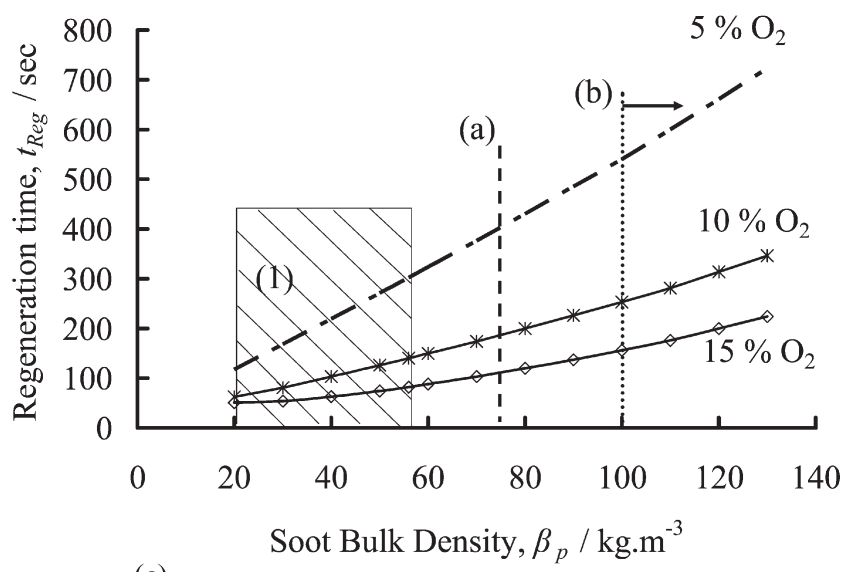

(c)

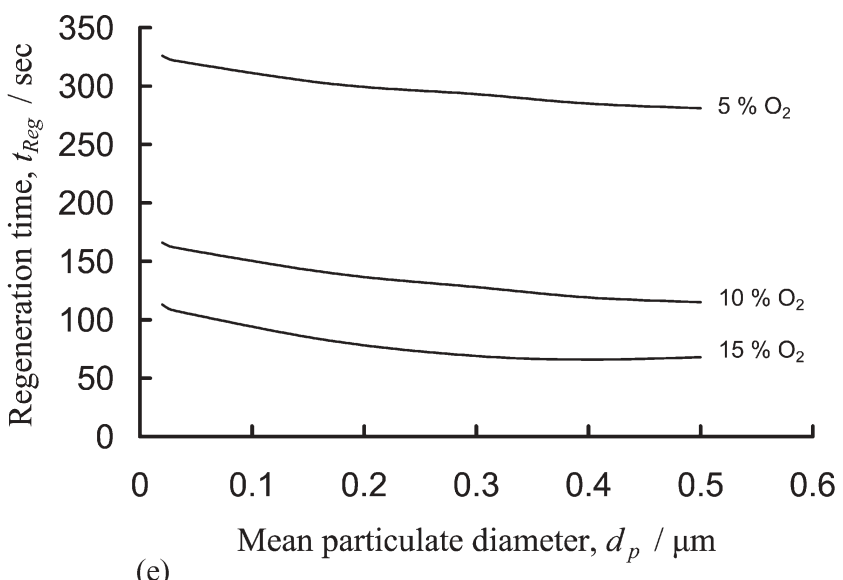

(e)

Fig. 6 Regeneration time as a function of (a) activation energy $E_{\mathrm{a}}$ for various engine exhaust gas oxygen concentrations, (b) frequency factor $A$ for various engine exhaust gas oxygen concentrations, (c) soot bulk density $\beta_{\mathrm{p}}$ for various oxygen concentrations [shaded area (1) and lines (a) and (b) show the values of $\beta_{p}$ used by other investigators], (d) soot porosity $\phi_{\mathrm{p}}$ for various oxygen concentrations and (e) mean soot particulate diameter $d_{\mathrm{p}}$ for various oxygen concentrations 


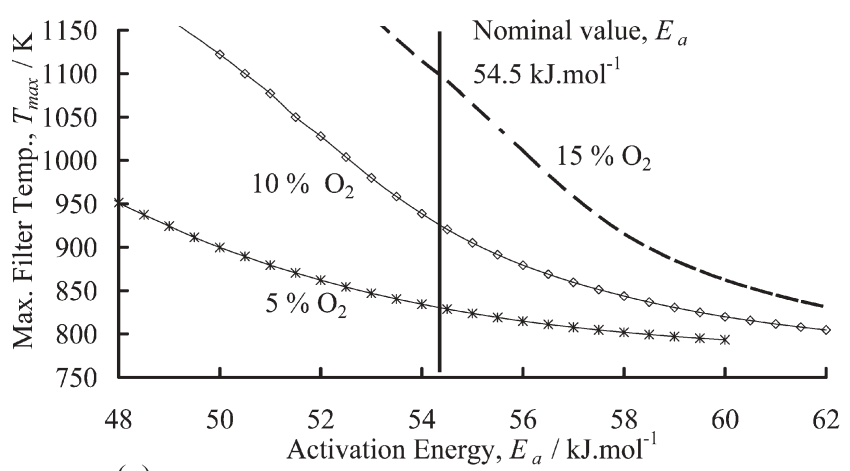

(a)

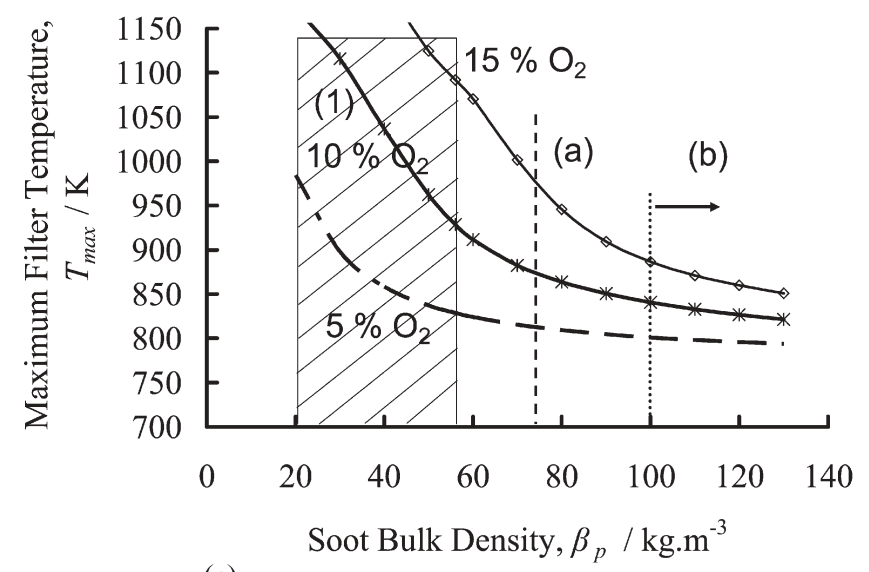

(c)

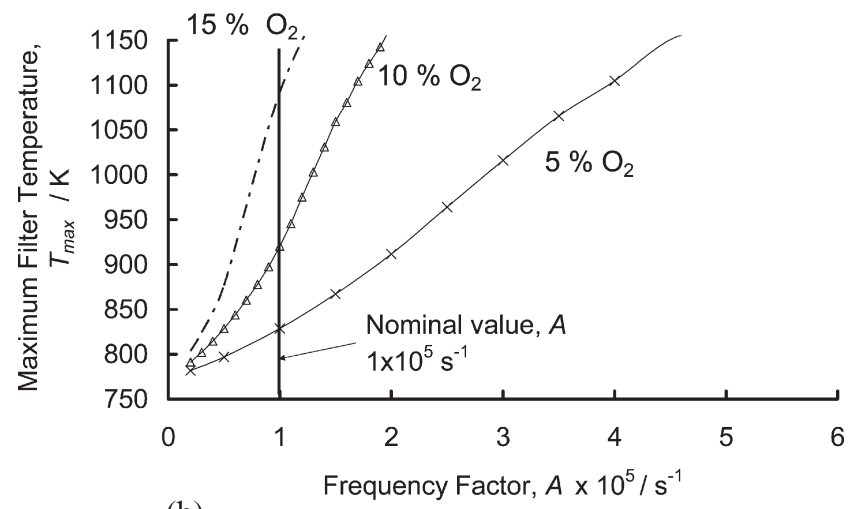

(b)

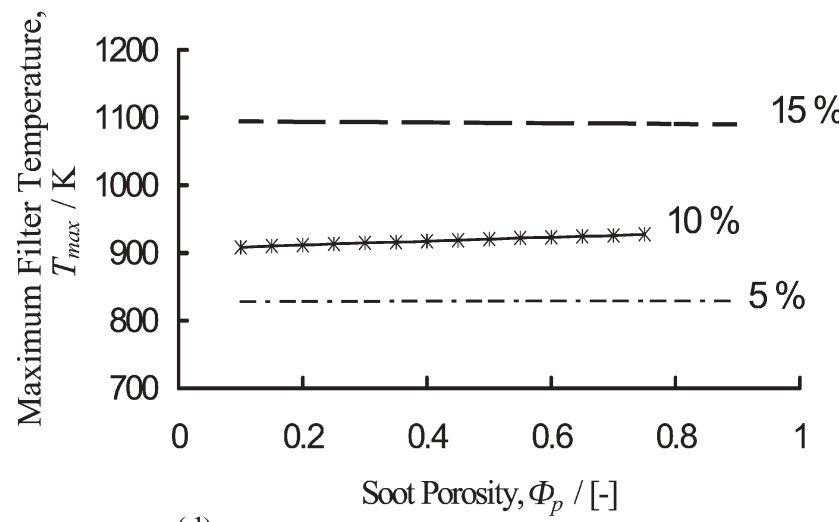

(d)

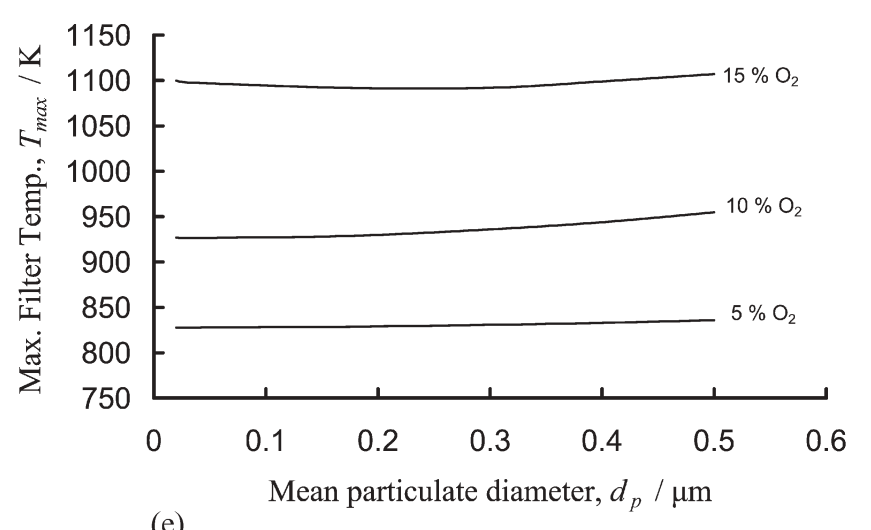

Fig. 7 Maximum filter temperature as a function of (a) activation energy of soot oxidation, $E_{\mathrm{a}}$ for various oxygen concentrations, (b) frequency factor $A$ for various oxygen concentrations, (c) soot bulk density $\beta_{\mathrm{p}}$ for various oxygen concentrations [shaded area (1) and lines (a) and (b) show the values of $\beta_{\mathrm{p}}$ used by other investigators], (d) soot porosity $\phi_{\mathrm{p}}$ for various oxygen concentrations, and (e) mean soot particulate diameter $d_{\mathrm{p}}$ for various oxygen concentrations

a mean decrease in regeneration time by a factor of more than 4 was obtained and a change of only a factor of 2 for an increase of 10-15 per cent. The data were curve fitted with exponential expressions and are summarized in Table 3; these are useful for parametric studies. From Table 3, it is observed that the trend of the graphs could be represented by exponential terms with different values of pre-exponential coefficients. It was found that the maximum filter temperature $T_{\max }$ increased more significantly as $E_{\mathrm{a}}$ decreased if a higher oxygen percentage was present.

The results obtained in this study are different from those of Miyairi et al. [8]. In their study, a different range of $E_{\mathrm{a}}$ was used, which was $50-150 \mathrm{~kJ} / \mathrm{mol}$. It was found that there exists a critical value of activation energy, beyond which the regeneration process deteriorates, i.e. the maximum filter temperature decreases and the regeneration time increases beyond practical limits. This 
Table 3 Analytical expressions for regeneration time obtained from curve fitting the model data obtained with different oxygen concentrations

\begin{tabular}{ll}
\hline $\begin{array}{l}\text { Oxygen percentage } \\
(\%)\end{array}$ & Curve-fitting equation \\
\hline 5 & $t_{\text {Reg }}=0.041 \exp \left(0.0002 E_{\mathrm{a}}\right)$ \\
10 & $t_{\text {Reg }}=0.0094 \exp \left(0.0002 E_{\mathrm{a}}\right)$ \\
15 & $t_{\text {Reg }}=0.0043 \exp \left(0.0002 E_{\mathrm{a}}\right)$ \\
\hline
\end{tabular}

observation was not obtained in this study. However, the general trend was observed with the parametric study of frequency factor $A$ (see later).

From Fig. 6b, it can be seen that there exists an exponential decay relationship between regeneration time and frequency factor. As the frequency factor $A$ increases, the values of regeneration time converge asymptotically. It can also be seen from the graph that, for a given value of activation energy, there exists a minimum value of frequency factor below which the regeneration time increases indefinitely. For example, for $E_{\mathrm{a}}=54.5 \mathrm{~kJ} / \mathrm{mol}$ and 5 per cent oxygen concentration, this minimum point is approximately $A=1.0 \times 10^{5} \mathrm{~s}^{-1}$. This phenomenon can be explained as follows: at $A=1.0 \times 10^{5} \mathrm{~s}^{-1}$, the reaction rate is sufficiently high to oxidize all the soot available but, since the loaded soot is kept constant, higher frequency factors can only decrease regeneration time slightly. However, it is observed that the maximum filter temperature changes linearly with $A$. With a higher oxygen concentration in the filter, it is expected that the rate of change in $T_{\max }$ with respect to $A$ would be higher. Curve fitting was employed to calculate the gradients and $y$ intercepts. The results are presented in Table 4 . The values of $y$ intercept are in good agreement with the exhaust gas temperature, which was $773 \mathrm{~K}$.

As shown in Fig. 6c, it could be observed that an approximately linear relationship between regeneration time and soot bulk density was obtained. The regeneration time increased with increasing bulk density and the effect was more significant as the oxygen concentration decreased. Conversely, the maximum filter temperature decreased with increasing bulk density (Fig. 7c). As the oxygen concentration increased, the rate of change in $T_{\max }$ became increasingly exponential.

The above observations can be accounted for by the following explanation. The higher bulk density means

Table 4 Results obtained from curve fitting with model data obtained with different oxygen concentrations

\begin{tabular}{lll}
\hline $\begin{array}{l}\text { Oxygen percentage } \\
(\%)\end{array}$ & $\begin{array}{l}\text { Gradient } \\
(\mathrm{K} / \mathrm{s})\end{array}$ & $\begin{array}{l}y \text { intercept } \\
(\mathrm{K})\end{array}$ \\
\hline 5 & $834.7 \times 10^{-6}$ & 756 \\
10 & $2066.2 \times 10^{-6}$ & 732 \\
15 & $3364.4 \times 10^{-6}$ & 728 \\
\hline
\end{tabular}

that the soot mass per unit volume is higher. Hence, the time taken to oxidize the soot completely will be longer. At constant porosity, but with increasing bulk density, it is more difficult for the oxygen to diffuse into the bulk interior to oxidize the soot. Therefore, the oxidation reaction is diffusion controlled. As a result, the maximum filter temperature is reduced. A similar result was obtained by Millet et al. [5]. In their model and experiments, they observed a peak temperature when the soot accumulated at the end of the inlet channel due to higher exhaust flowrate. Accordingly, this caused a higher bulk density of soot than when it was evenly distributed over the inlet channel. Hence, based on the assertions, this peak temperature can be attributed from the higher soot and oxygen content availabilities for the regeneration process.

Figure 6d shows the profiles of regeneration time versus bulk porosity. At 5, 10 and 15 per cent oxygen concentrations, the durations taken to oxidize the soot completely are approximately 300,140 and 85 s respectively. The changes can be considered as approximately linear. The slopes are found to be 11.3, 23.1 and $16.3 \mathrm{~s}$ respectively per unit porosity.

Figure $7 \mathrm{~d}$ shows the maximum filter temperature at various porosity values. At 5 per cent oxygen concentration, the temperature change is almost negligible. At 10 per cent, it can be expected to have an average change of $2 \mathrm{~K}$ for every 0.1 change in porosity. At 15 per cent, it shows a non-linear relationship between filter temperature and bulk porosity.

The soot oxidation rate increased as the mean particulate diameter increased from $20 \mathrm{~nm}$ to $0.5 \mu \mathrm{m}$ (see Figs $6 \mathrm{e}$ and $7 \mathrm{e})$. The trend is understandable since the heat transfer coefficient [equation (15)] of the soot layer is inversely proportional to the mean particulate diameter. As the particulate diameter increases, the specific area of the particulate decreases and this in turn decreases the heat transfer coefficient of the soot layer. As a result, combustion heat that is generated is unable to dissipate quickly, thereby increasing the maximum filter temperature and higher soot oxidation rate. The same reasoning can be used to explain the trend of the model result with respect to soot bulk porosity. Note that the heat transfer coefficient of the soot layer is also a function of exhaust flowrate. Thus, the sensitivities of the bulk porosity and mean particulate diameter can be examined for different exhaust flowrates (or engine speeds). The effect of engine speed on regeneration rate was shown elsewhere [7]. Under the present conditions, neither parameter shows a significant effect on the DPF regeneration rate.

\section{RANK OF IMPORTANCE OF PARAMETERS}

In order to rank the relative importance of the parameters, graphs of maximum filter temperature and regeneration time are plotted against the percentage change of parameters as shown in Fig. 8. From the 


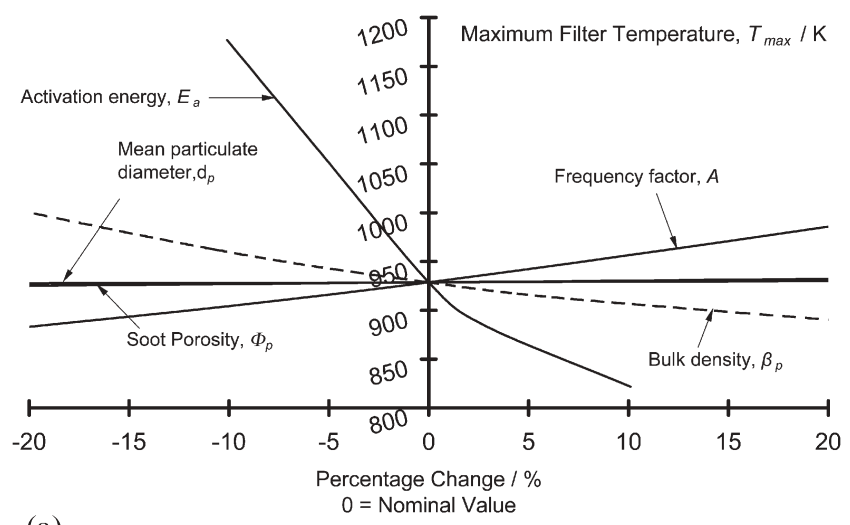

(a)

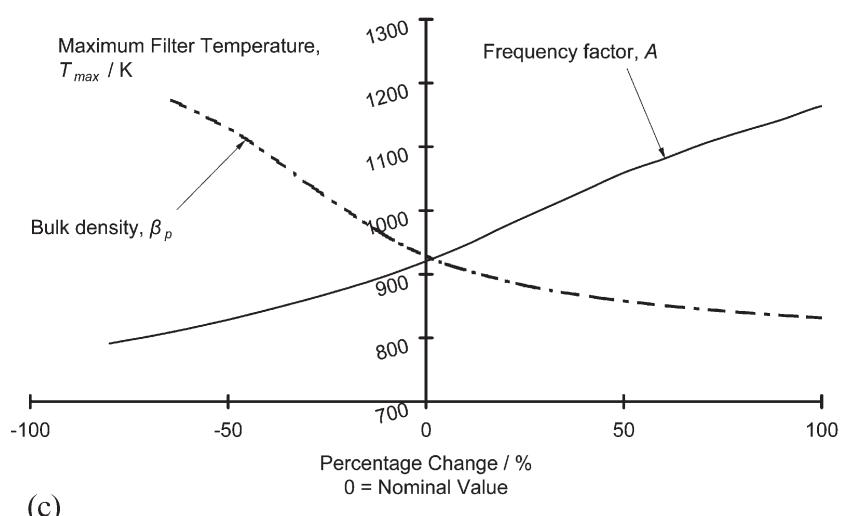

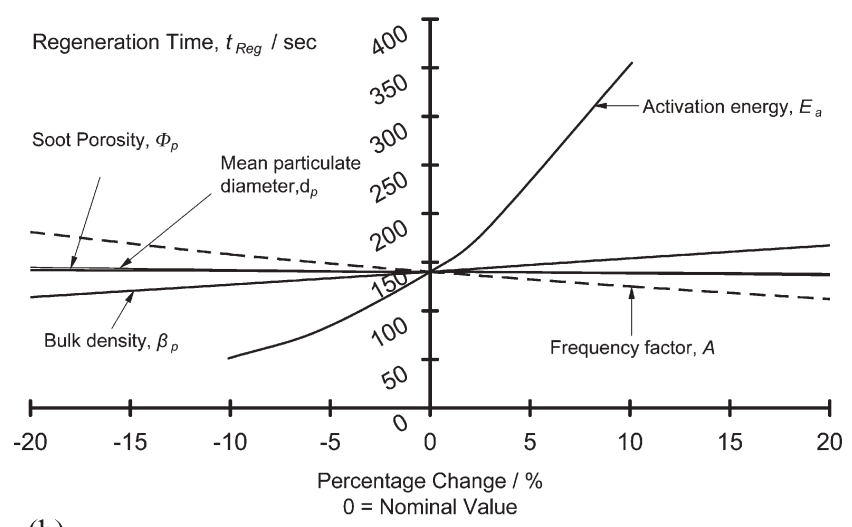

(b)

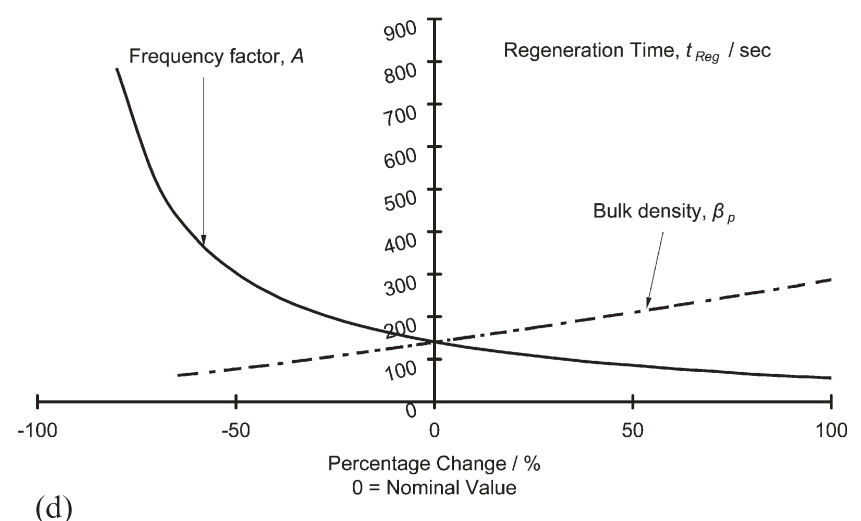

(d)

Fig. 8 (a) Comparison of relative importance of the four parameters $E_{\mathrm{a}}, A, \beta_{\mathrm{p}}, \phi_{\mathrm{p}}$ and $d_{\mathrm{p}}$ on maximum filter temperature during regeneration. (b) Comparison of relative importance of the five parameters $E_{\mathrm{a}}, A, \beta_{\mathrm{p}}, \phi_{\mathrm{p}}$ and $d_{\mathrm{p}}$ on filter regeneration time. (c) Comparison of relative importance of the frequency factor $A$ and soot bulk density $\beta_{\mathrm{p}}$ on maximum filter temperature during regeneration. (d) Comparison of relative importance of the frequency factor $A$ and soot bulk density $\beta_{\mathrm{p}}$ on regeneration time

graphs, useful trends are observed. The activation energy showed the highest sensitivity of the five parameters, whereas the responses of porosity and mean particulate diameter were negligible. The sensitivities shown by the frequency factor and soot bulk density have approximately the same order-of-magnitude effect on both regeneration temperature and time. However, the bulk density has a more linear behaviour over the range studied (Figs 8c and d) than the frequency factor.

These results have significant value for filter regeneration model development. They show clearly the most important parameters that require close attention in model development and in experimental investigations.

\section{CONCLUSIONS}

Several useful conclusions can be drawn from this study:

1. The regeneration characteristics of diesel filters have been theoretically analysed. The model predictions have been shown previously to compare well with experimental data.
2. The modelling parametric study shows that overall regeneration time is governed by the exhaust gas oxygen concentration and not the particulate mass loading or exhaust gas flowrate. However, to ensure that the filter does not exceed safe temperature limits during regeneration, the filter should be regenerated at particulate mass loadings not exceeding 25 per cent of the filter's total capacity.

3. The model presented can be modified for applying to other filter types such as fibrous mesh and foams.

4. The importance of soot inherent properties on the regeneration behaviour of the DPF is highlighted. The particulate/soot activation energy $E_{\mathrm{a}}$ has the greatest effect in this respect. It is followed by frequency factor $A$, the bulk density $\beta_{\mathrm{p}}$ (both are of the same rank), the porosity $\phi_{\mathrm{p}}$ and mean particulate diameter $d_{\mathrm{p}}$ (both are of the same rank). These require close attention in model development and experimental studies.

5. For every given value of activation energy $E_{\mathrm{a}}$, there is a range of frequency factors that have a linear effect on the regeneration process. Below this range, the reaction rate is too slow for practical filter regeneration. 
6. Lower oxygen concentration in exhaust gas flow has a stronger effect on the regeneration behaviour of soot in the DPF than a high concentration of oxygen. This means that diffusion-controlled regeneration behaviour should be taken into account in models, as was done in the present model.

7. The findings of this work can be used in parametric studies of DPF behaviour.

\section{ACKNOWLEDGEMENTS}

The authors wish to thank Perkins Engines, The Royal Academy of Engineering, the Engineering and Physical Sciences Research Council (EPSRC) and Loughborough University for supporting this work.

\section{REFERENCES}

1 Johnson, J. H., Bagley, S. T., Gratz, L. D. and Leddy, D. G. A review of diesel particulate control technology and emissions effects, 1992 Horning Memorial Award Lecture. SAE paper 940233, 1994.

2 Harano, A., Murata, K., Takamizawa, K. and Sadakata, M. Oxidation of carbonaceous particles in silent discharge reactor. J. Chem. Engng Japan, 1998, 31(5), 700-705.

3 Bissett, E. J. Mathematical model of the thermal regeneration of a wall-flow monolith diesel particulate filter. Chem. Engng Sci., 1984, 39(7/8), 1233-1244.

4 Kandylas, I. P., Haralampous, O. A. and Koltsakis, G. C. Diesel soot oxidation with $\mathrm{NO}_{2}$ : engine experiments and simulations. Ind. Engng Chemistry Res., 2002, 41, 5372-5384.

5 Millet, C.-N., Menegazzi, P., Martin, B., Colas, H. and Bourgeois, C. Modeling of diesel particulate filter regeneration: effect of fuel-borne catalyst. SAE paper 2002-01-2786, 2002.

6 Konstandopolous, A. G., Kostoglou, M., Housiada, P., Vlachos, N. and Zarvalis, D. Multichannel simulation of soot oxidation in diesel particulate filters. SAE paper 2003-01-0839, 2003.

7 Garner, C. P. and Dent, J. C. A thermal regeneration model for monolithic and fibrous diesel particulate traps. $S A E$ Trans., J. Passenger Cars, 1988, 97(4), 9-24.

8 Miyairi, Y., Miwa, S., Abe, F., Xu, Z. and Nakasuji, Y. Numerical study on forced regeneration of wall-flow diesel particulate filters. SAE paper 2001-01-0912, 2001.

9 Bissett, E. J. and Shadman, F. Thermal regeneration of diesel particulate monolithic filters. Am. Inst. Chem. Engrs J., 1985, 31(5), 753-758.

10 Higuchi, N., Mochida, S. and Kojima, M. Optimized regeneration conditions of ceramic honeycomb diesel particulate filters. SAE paper 830078, 1983.

11 Lawson, D. A. and Norbury, J. Combustion in a porous medium. In Proceedings of the Third International Conference on Numerical Methods in Thermal Problems,
Seattle, Washington, 1983, pp. 849-859 (Pineridge Press, Swansea).

12 Verrant, J. A. and Kittelson, D. B. Sampling and physical characterization of diesel aerosols. SAE paper 77720, 1977.

13 Wade, W. R., White, J. E. and Florek, J. J. Diesel particulate trap regeneration techniques. SAE paper 810118, 1981.

14 Otto, K., Sieg, M. H., Zinbo, M. and Bartosiewicz, L. The oxidation of soot deposits from diesel engines. SAE paper 800336, 1980.

15 Howitt, J. S. and Montierth, M. R. Cellular ceramic diesel particulate filter. SAE paper 810114, 1981.

16 Mogaka, Z. N., Wong, V. W. and Shahed, S. M. Performance and regeneration characteristics of a cellular ceramic diesel particulate trap. SAE paper 820272, 1982.

17 Thoenes, D. and Kramers, H. Mass transfer from spheres in various regular packings to a flowing fluid. Chem. Engng Sci., 1958, 8, 271-283.

18 Opris, C. N. and Johnson, J. H. A 2-D computational model describing the flow and filtration characteristics of a ceramic diesel particulate trap. SAE paper 980545, 1998.

19 Gilot, P., Bonnefoy, F., Marcuccilli, F. and Prado, G. Determination of kinetic data for soot oxidation. Modeling of competition between oxygen diffusion and reaction during thermogravimetric analysis. Combust. Flame, 1993, 95(1-2), 87-100.

20 Garner, C. P. The regeneration of monolithic wall-flow diesel particulate traps. $\mathrm{PhD}$ Thesis, Loughborough University, 1989.

21 Ahlström, A. F. and Odenbrand, C. U. I. Combustion characteristics of soot deposits from diesel engines. Carbon, 1989, 27(3), 475-483.

22 Pattas, K. N., Kyriakis, N. A. and Samaras, Z. C. A new approach to the oxidizing behavior of a porous ceramic diesel particulate trap. SAE paper 850012, 1985.

23 Field, M. A., Gill, D. W., Morgan, B. B. and Hawksley, P. G. W. Combustion of Pulverised Coal, 1967 (British Coal Utilization Research Association, Leatherhead, Surrey).

24 Pauli, E., Lepperhoff, G. and Pischinger, F. The description of the regeneration behaviour of diesel particulate traps with the aid of a mathematical model. SAE paper 830180, 1983.

25 Wiedemann, B., Doerges, U., Wengeler, W. and Poettner, B. Regeneration of particulate filters at low temperatures. SAE paper 830086, 1983.

26 Olson, K. E., Luss, D. and Amundson, N. R. Regeneration of adiabatic fixed beds. Ind. Engng Chemistry Process Des. Dev., 1968, 7, 96-100.

27 Bear, J. and Corapcioglu, M. Y. Fundamentals of Transport Phenomena in Porous Media, 1985 (Martinus Nijhoff, Dordrecht).

28 Hashimoto, S., Miyairi, Y., Hamanaka, T., Matsubara, R., Harada, T. and Miwa, S. SiC and cordierite diesel particulate filters designed for low pressure drop and catalyzed, uncatalyzed systems. SAE paper 2002-01-0322, 2002.

29 Kittelson, D. B. Engines and nanoparticles: a review. J. Aerosol Sci., 1998, 29, 575-588. 